\title{
Pesquisas empíricas sobre o processo de ensino-aprendizagem em língua materna na Educação Profissional Técnica de Nível Médio Subsequente
}

\author{
Empirical research about the native language teaching-learning process in the \\ Subsequent Professional Technical Secondary Education
}

\author{
Raquel Darelli Michelon (iD https://orcid.org/0000-0003-0892-6863 \\ Instituto Federal de Educação, Ciência e Tecnologia de Santa Catarina (IFSC) \\ e-mail-raquelmichelonmestrado@gmail.com \\ Salete Valer (iD https://orcid.org/0000-0002-9391-3807 \\ Instituto Federal de Educação, Ciência e Tecnologia de Santa Catarina (IFSC) \\ e-mail - salete.valer@ifsc.edu.br
}

\begin{abstract}
Resumo
Com o projeto de expansão dos Institutos Federais a partir de 2008, produções científicas sobre ensino-aprendizagem voltados à Educação Profissional passam a ser ampliadas. Nesse contexto, o objetivo deste artigo é identificar as pesquisas empíricas recentes sobre o processo de ensinoaprendizagem de língua materna na Educação Profissional Técnica de Nível Médio Subsequente. Isso para mapear o conjunto significativo de investigações divulgadas dessa área. A metodologia toma por base a modalidade principal de pesquisa, a análise de conteúdo, em que, por meio de diferentes descritores, buscam-se, em portais como CAPES, Google Acadêmico e SciELO, entre os anos de 2008 e 2018, textos científicos sobre o objeto investigado. Após a identificação das pesquisas, fez-se a descrição e a análise dos dados, relacionando-os com as bases teóricas da EPT e do ensino-aprendizagem de língua materna. Os resultados apontam que os artigos científicos encontrados pelo recorte desta pesquisa não enfocam o letramento em língua materna por meio dos gêneros discursivos/textuais como unidade principal do processo pedagógico. Infere-se, assim, que as produções científicas sobre esse campo do conhecimento ainda são escassas e não dão conta das teorias que fundamentam a prática pedagógica do ensino de linguagem na EPT. Ressalta-se, portanto, a relevância de produzir estudos específicos na área da linguagem a fim de contribuir para a melhor compreensão do ensino-aprendizagem da língua materna na Educação Profissional Técnica de Nível Médio Subsequente.
\end{abstract}

Palavras-chave: Língua portuguesa. Educação profissional. Processo de ensino-aprendizagem.

\begin{abstract}
With the Federal Institutes expansion project since 2008, scientific productions about teaching and learning turned to professional education has increased. In this context, the object of this article is to identify recent empirical research about the native language teaching and learning process in the Subsequent Professional Technical Secondary Education, with the intent to map the significant set publications in this area. The methodology is based on the mains research modality, content analysis, that is, by different keywords, searched, sources like CAPES, Google Academic and SciELO, between 2008 and 2018, scientific texts about the investigated subject. After the identification of the articles, the data described and then analyzed, correlating them with the theories of Professional
\end{abstract}


Education and native language teaching and learning. The results suggest that the articles that were found by this research do not have as a focus the literacy in native language by means of discursivetextual genres like the pedagogic process main unity. It is inferred, thus, that the scientific production in this area is scarce and do not approach the theories that base the teaching and learning pedagogic in Professional Education. Finally, reinforcing, the relevance to produce specific studies in the language area with the intent to contribute to a better comprehension the native language teaching and learning process in the Subsequent Professional Technical Secondary Education.

Keywords: Portuguese language. Professional education. Teaching-learning process.

\section{Introdução}

A finalidade da educação nos espaços formais, em especial na Educação Básica, conforme o Capítulo II, Art. 22, da Lei de Diretrizes e Bases da Educação Nacional (BRASIL, LDB, 1996), é "[...] desenvolver o educando, assegurar-lhe a formação comum indispensável para o exercício da cidadania e fornecer-lhe meios para progredir no trabalho e em estudos posteriores". Para complementar o compromisso do Estado com a educação, já estabelecido no Capítulo III, Art. 205, da Constituição Brasileira (BRASIL, CB, 1988), a Lei n 11.741 de 16 de julho de 2008 (BRASIL, Lei 11741, 2008) institucionaliza, em seu Art. 39, a Educação Profissional e Tecnológica (EPT) como integrante aos "[...] diferentes níveis e modalidades de educação e às dimensões do trabalho, da ciência e da tecnologia". Além dessa especificação, no $\S 1^{\circ}$ desse mesmo artigo está prevista a organização dos cursos de Educação Profissional e Tecnológica por eixos tecnológicos, o que possibilita a "[...] construção de diferentes itinerários formativos, observadas as normas do respectivo sistema e nível de ensino".

Em acréscimo, a Lei 11.892 de 29 de dezembro de 2008 (BRASIL, Lei 11892, 2008) institui a Rede Federal Profissional, Científica e Tecnológica, criando os Institutos Federais (IF) e expandindo, portanto, a rede de educação profissional de modo a abranger todo o território nacional. Cabe ressaltar que, anteriormente à promulgação dessa lei, desde 2003, ocorreram discussões acerca dos princípios norteadores da educação profissional, as quais resultaram nas propostas constantes no Documento Base da Educação Profissional Técnica de Nível Médio Integrada ao Ensino Médio (BRASIL, DB, 2007), cujo objetivo, especialmente, foi o de afirmar os princípios para uma educação integral dos sujeitos trabalhadores. Afinal, é necessário que os sujeitos conheçam a si próprios para que possam ressignificar suas ações no mundo, já que a formação profissional deve ampliar a "[...] compreensão das dinâmicas socioprodutivas das sociedades modernas, com as suas conquistas e os seus revezes, e também habilitar as pessoas para o exercício autônomo e crítico de profissões, sem nunca se esgotar a elas" (BRASIL, DB, 2007, p. 45). Também são documentos organizadores da oferta da Educação Profissional Técnica de Nível Médio, a Resolução $n^{\circ}$ 6, de 20 de setembro de 2012 e o Parecer CNE/CEB n¹1/2012 (BRASIL, Parecer n 11, 2012), como se verá no referencial teórico.

Em 2017, a Lei $n^{\circ}$ 13.415/2017 (BRASIL, Lei $n^{\circ} 13.415,2017$ ), em um movimento de ruptura com as propostas anteriores, alterou a Lei de Diretrizes e Bases da Educação Nacional, estabelecendo uma mudança na estrutura do Ensino Médio que foi delineada por meio de uma nova organização curricular flexibilizada. Com essa alteração, são propostos itinerários formativos que devem ser escolhidos pelos estudantes, os quais focalizam as áreas de conhecimento e a formação técnica e 
profissional, favorecendo uma formação fragmentada. Essa perspectiva para a Educação Profissional Técnica de Nível Médio está explicitada na última versão da Base Nacional Comum Curricular (BRASIL, BNCC, 2017), publicada em 2017. Apesar das orientações curriculares propostas na nova BNCC, este trabalho assume pressupostos e direções apontados pelas duas versões anteriores do documento, por dialogarem com a proposta de Educação Profissional cujo objetivo é a formação integral dos sujeitos para a vida em sociedade.

Dentro dessa perspectiva, o objeto da presente investigação são as pesquisas empíricas sobre o processo de ensino-aprendizagem da Língua Portuguesa na Educação Profissional Técnica de Nível Médio, priorizando aquelas dos cursos técnicos subsequentes. A motivação para essa escolha advém da necessidade de se conhecer quais estratégias didáticas tem-se utilizado para 0 ensinoaprendizagem de língua materna na EPT e em que medida essas práticas pedagógicas estão embasadas pelos princípios da Educação Profissional conforme se assume nesta investigação. Na compreensão de uma proposta como essa, a linguagem é considerada um dos componentes curriculares relevantes na EPT. Conforme postula a LDB em seu Art. 36, a língua materna deve ser ensinada no Ensino Médio a fim de garanti-la como um "[...] instrumento de comunicação, acesso ao conhecimento e exercício da cidadania" (BRASIL, LDB, 1996), uma vez que ela é ferramenta essencial para as mais diversas situações didáticas. O uso da língua materna em sua modalidade oral ou escrita por qualquer componente curricular requer a indissociabilidade entre ensino e contexto de aprendizagem em todas as modalidades de formação.

É sabido também que uma das causas da exclusão social é o déficit de letramento de práticas sociais delegadas ao ensino formal que atinge um grande número sujeitos os quais não tiveram oportunidade de progredir em seus estudos, dada a própria estrutura capitalista. Esses indivíduos substanciam a classe trabalhadora e têm o direito a uma educação que os faça sentir incluídos. É por isso que, conforme postula Frigotto (1991, p. 270), "[...] a concepção de ensino e formação politécnica é, antes de tudo, uma crítica radical ao projeto excludente, elitista e diferenciador do ensino e da formação, desenvolvido na sociedade capitalista". Sendo assim, é preciso embasar as práticas pedagógicas apoiadas sempre em reflexões teóricas acerca tanto do papel quanto da natureza da educação na sociedade sob esse regime.

Nesse sentido, cabe aos IFs essa formação integral focada nos indivíduos e não no mercado de trabalho. Sobre essa formação, Pacheco (2010), ex-secretário da Educação Profissional e Tecnológica do Ministério da Educação, apresenta uma proposta contextualizada,

[...] banhada de conhecimentos, princípios e valores que potencializam a ação humana na busca de caminhos de vida mais dignos. Assim, derrubar as barreiras entre o ensino técnico e o científico, articulando trabalho, ciência e cultura na perspectiva da emancipação humana, é um dos objetivos basilares dos Institutos. Sua orientação pedagógica deve recusar o conhecimento exclusivamente enciclopédico, assentando-se no pensamento analítico (PACHECO, 2010, p. 14).

Essa perspectiva compreende, então, uma profissionalização mais ampla, contribuindo com a abertura de infinitas possibilidades para os sujeitos nela inseridos. Nessa proposta educativa, a adequada utilização da linguagem passa a ser ferramenta imprescindível nas relações sociais em todas as esferas 
comunicativas, sendo acessada pelos sujeitos por meio do letramento em língua materna. Assim, torna-se relevante também no contexto da EPT de Nível Médio, estando associado ao desenvolvimento cognitivo e linguístico dos sujeitos estudantes. Dessa forma, pode-se perceber a importância dessas instituições para o projeto de uma sociedade inclusiva e justa, por meio de uma educação sem dicotomias.

O problema desta investigação pode ser colocado no âmbito da relação intrínseca entre a relevância do letramento em língua materna e a proposta de uma educação profissional politécnica em que a emancipação do sujeito trabalhador se concretiza por via da linguagem. Nesse sentido, por meio do levantamento de pesquisas científicas realizadas sobre o objeto de investigação, o ensino-aprendizagem da língua materna na EPT de nível médio, pode-se conhecer o que os pesquisadores da área investigaram e divulgaram para a comunidade acadêmica. Além disso, o recorte desse estudo é importante, pois evidencia as bases conceituais da educação politécnica, em que o saber historicamente construído é democraticamente também distribuído, visando a uma formação plena contrária a uma instrução adestradora.

Tal perspectiva de educação busca a emancipação da classe trabalhadora, ao mesmo tempo em que concebe uma sociedade mais justa e igualitária e que possibilite, conforme Ramos (2008, p. 3), "[...] a compreensão dos princípios científico-tecnológicos e históricos da produção moderna, de modo a orientar os estudantes à realização de múltiplas escolhas". Nessa relação, a educação politécnica objetiva a um desenvolvimento integral do indivíduo, o que se estende também para o ensino e a aprendizagem da língua materna. Ao se particularizar o tema proposto, traçou-se como objetivo geral identificar as pesquisas empíricas recentes sobre o processo de ensino-aprendizagem de língua materna na Educação Profissional Técnica de Nível Médio Subsequente. A busca por essas pesquisas abrange textos científicos divulgados em diferentes plataformas digitais a partir de 2008, ano de criação dos Institutos Federais. Essa pesquisa se justifica pela necessidade de compreender melhor os objetos que estão sendo investigados em relação ao ensino-aprendizagem da Língua Portuguesa na Educação Profissional Técnica de Nível Médio Subsequente.

Nessa relação, os resultados do mapeamento dos estudos empíricos sobre os objetos de ensino-aprendizagem da Língua materna na EPT de Nível Médio, contribuem no sentido de se observar a forma como o letramento em língua materna está sendo trabalhado nesse contexto educativo, especialmente, no sentido de se depreender a relevância desse saber para a concretização da proposta da educação politécnica, enfatizando-se o binômio teoria-prática para a formação integral do sujeito estudante e trabalhador. Os resultados deste trabalho contribuem com as pesquisas no campo da Educação Profissional e Tecnológica e da comunidade acadêmica de modo geral. Colabora, ainda, apontando possíveis lacunas existentes em relação ao objeto de estudo, fornecendo o embasamento para a defesa de pesquisas futuras.

\section{A educação profissional politécnica}

Conforme consta no documento das Diretrizes Curriculares Nacionais Gerais da Educação Básica (BRASIL, DCNGEB, 2013), atendendo à proposta da Lei $n^{\circ}$ 
11741/2008, a Educação Profissional, sendo uma modalidade na educação básica de nível médio, possui como eixos norteadores as dimensões do trabalho, da ciência, da tecnologia e da cultura. Esses elementos devem permear o processo de ensino-aprendizagem escolar, favorecendo uma educação profissional politécnica, em que o pensar o mundo e o agir nele não sejam ações antagônicas, mas integradas. Com o objetivo de complementar a perspectiva educacional proposta pelos documentos citados, a Resolução $n^{\circ}$ 6, de 2012, que define as Diretrizes Curriculares Nacionais para a Educação Profissional Técnica de Nível Médio, esclarece a finalidade dos cursos pertencentes a essa modalidade de ensino, proporcionando "[...] ao estudante conhecimentos, saberes e competências profissionais necessários ao exercício profissional e da cidadania, com base nos fundamentos científico-tecnológicos, sócio-históricos e culturais" (BRASIL, Res. $\mathrm{n}^{\circ}$ 6, 2012, p. 2). Esses fundamentos, por sua vez, denotam a importância das dimensões trabalho, ciência, tecnologia e cultura como indissociáveis para a formação humana e a oferta dos cursos, segundo consta nesse documento, deve estar articulada a esses eixos.

Para tal vinculação, essa mesma resolução apresenta, entre os princípios norteadores que devem permear a EPT de Nível Médio, (i) a formação integral, por meio da relação e articulação entre formação geral e formação profissional para um desenvolvimento pleno; (ii) o trabalho assumido como princípio educativo; (iii) a pesquisa entendida como um princípio pedagógico por meio da indissociabilidade entre teoria e prática no processo de ensino-aprendizagem; e (iv) a interdisciplinaridade presente na prática pedagógica com objetivo de favorecer a contextualização e superar a fragmentação do conhecimento. São esses fundamentos, segundo o documento, que promovem uma melhora na qualidade pedagógica com maior perspectiva de efetividade social, a fim de garantir o acesso, a permanência, o sucesso e o êxito do sujeito aprendiz tanto em seu percurso de formação escolar como em sua incorporação na vida social e profissional.

A finalidade educacional de desenvolver capacidades críticas para que os sujeitos garantam sua inserção tanto no mundo do trabalho como na vida social é fundamentada em uma base histórico-crítica pautada em estudos marxistas como os de Saviani (1989), Frigotto, Ciavatta e Ramos (2005) e outros que discorreram sobre o tema. Essas bases conceituais subsidiam as Diretrizes Curriculares Nacionais Gerais da Educação Básica (BRASIL, DCNGEB, 2013), documento que compreende a duplicidade semântica a que a palavra trabalho faz referência, apresentando tanto uma perspectiva ontológica como uma perspectiva histórica. Segundo as Diretrizes, pelo sentido ontológico, "[...] o trabalho é princípio educativo à medida que proporciona a compreensão do processo histórico de produção científica e tecnológica" (BRASIL, DCNGEB, 2013, p. 163). Pelo sentido histórico "[...] o trabalho é princípio educativo na medida em que coloca exigências específicas para o processo educacional, visando à participação direta dos membros da sociedade no trabalho socialmente produtivo" (BRASIL, DCNGEB, 2013, p. 163). Há assim a organização de uma base unitária de ensino e a fundamentação da formação específica.

Uma vez compreendido como ato educativo, o trabalho relaciona-se diretamente com a educação e essa relação é então indispensável na composição curricular de uma formação politécnica. Acrescenta-se a essa concepção do trabalho como princípio educativo o princípio pedagógico da pesquisa, que solidifica a construção do conhecimento científico e tecnológico no contexto da Educação Profissional, 
além de favorecer o desenvolvimento de habilidades cognitivas como interpretar, relacionar, analisar, criticar, refletir, rejeitar ideias fechadas, aprender, buscar soluções, propor alternativas etc. (BRASIL, DCNGEB, 2013, p. 164). O desenvolvimento e aprimoramento dessas habilidades cognitivas são necessárias para que os sujeitos estudantes e trabalhadores alcancem acesso-permanênciasucesso-progressão no estudo e no mundo do trabalho.

Para a manutenção dessa perspectiva de formação politécnica, a atividade escolar da pesquisa como princípio pedagógico deve ser mediada por docentes que assumam a tarefa de orientar e motivar as práticas de pesquisa. Sobre a contribuição dessa metodologia didática para a formação discente, o mesmo documento esclarece como essa atividade é relevante e amplia o desenvolvimento da capacidade de pesquisa, a qual

[...] propicia o desenvolvimento da atitude científica, o que significa contribuir, entre outros aspectos, para o desenvolvimento de condições de, ao longo da vida, interpretar, analisar, criticar, refletir, rejeitar ideias fechadas, aprender, buscar soluções e propor alternativas, potencializadas pela investigação (BRASIL, DCNGEB, 2013, p. 218).

Segundo o mesmo documento (BRASIL, DCNGEB, 2013, p. 19), o desenvolvimento dessas habilidades cognitivas representam um desafio que, ao ser posto em prática, gera grande impacto social por romper com a dualidade existente entre uma formação geral promovida às classes abastadas e uma formação profissional e técnica para as classes desfavorecidas. Nesse sentido, Saviani (2003) defende o ensino politécnico, atribuindo à noção de politecnia o postulado de que o processo de trabalho deve desenvolver "[...] em uma unidade indissolúvel, os aspectos manuais e intelectuais" (SAVIANI, 2003, p. 138). A indissociabilidade entre formação geral e formação profissional garante ao estudante trabalhador o domínio dos fundamentos de processo produtivo, o que envolve uma compreensão global da realidade. Assim, consequentemente, tem-se um processo de formação integral, cultural e intelectual emancipatório, uma vez que possibilita a atuação dos sujeitos com autonomia e consciência do arranjo social, político e econômico da sociedade.

\section{Ensino-aprendizagem da língua materna na formação geral e na EPT}

Uma vez compreendido o caráter indissociável entre formação geral e formação profissional proposto pela ideologia de educação politécnica, entende-se que os pressupostos teórico-metodológicos assumidos para o ensino-aprendizagem de língua materna na EPT são complementares aos assumidos para a formação geral. Primeiramente, deve-se reconhecer a escola como um importante agente de letramento. É nesse campo, então, que o termo letramento ganha relevância, pois é um conceito que trata da relação que um grupo ou uma pessoa, em suas atividades sociais, mantém principalmente com a escrita, seja por habilidades individuais, como, por exemplo, em práticas de leitura e de produção textual, seja pelo uso dessas habilidades nas práticas sociais em que esteja inserido. A escola é, pois, responsável pelo desenvolvimento dos conhecimentos linguísticos necessários em diferentes contextos comunicacionais. Para Soares (1998, p. 39) o letramento resulta da "[...] ação de ensinar e aprender as práticas sociais de leitura e escrita. O estado ou condição que adquire um grupo social ou um indivíduo como consequência de ter-se apropriado da escrita e de suas práticas sociais", 
resultando, portanto, em mudanças sociais, culturais, cognitivas e linguísticas nos sujeitos.

Há, no país, vastas pesquisas nessa área entre as quais estão Kleiman, 1995; Rojo, 1998; Soares, 1998 etc., as quais, em consonância, estabelecem que os sujeitos estão expostos às práticas de letramento mesmo antes de iniciarem o ciclo escolar. Em conformidade a essas pesquisas, as autoras Melo e Cavalcante (2006, p. 113) salientam que o letramento escolar é importante, pois garante a inserção dos estudantes "[...] no mundo da escrita [...]", mas deve haver uma relação entre o letramento escolar e outros letramentos sociais. Segundo essas autoras, por meio dessa relação, o estudante amplia "[...] seu domínio da língua na oralidade e na escrita em sua multiplicidade de aspectos contextuais, com vistas à atuação social plena" (MELO; CAVALCANTE, 2006, p. 114). Os estudos envolvendo essa perspectiva contribuem, portanto, para a formulação de programas educacionais que consideram as exigências de letramento dentro e fora da escola, promovendo, assim, a inclusão social dos sujeitos por meio de práticas de leitura e escrita necessárias para a efetiva participação social dos sujeitos.

Na segunda edição da BNCC, consta que o letramento é "[...] entendido como uma condição que permite ler e escrever em diversas situações pessoais, sociais e escolares" (BRASIL, BNCC, 2016, p. 87), necessitando que diversas práticas de oralidade, leitura e escrita constituam o letramento escolar. A última versão desse documento acrescenta, para o ensino de língua materna, a necessidade de compreensão do letramento não somente em torno da palavra escrita ou da cultura do impresso, mas considerando também as práticas contemporâneas de linguagem, como "a cultura digital, os multiletramentos, os novos letramentos, entre outras denominações que procuram designar novas práticas sociais e de linguagem" (BRASIL, BNCC, 2017, p. 478). Essa determinação aponta para o papel da escola como agência de mediação nesse processo de desenvolvimento dos sujeitos estudantes.

Essa perspectiva para a ampliação das ações de linguagem, que contribui para o desenvolvimento do letramento, já aparece em diferentes documentos de políticas públicas educacionais, como as Orientações Curriculares para o Ensino Médio (BRASIL, OCEM, 2006). Esse documento apresenta discussões sobre a importância da construção de sentidos em sala de aula, sob a justificativa de que o processo de ensino-aprendizagem, nessa etapa, não é conclusivo. Essa projeção que a educação básica deve proporcionar aos alunos influencia também o ensino da língua portuguesa, o qual não deve ser pensado fora do contexto social, mas em consonância com a ideia de que o sujeito tem o direito de compreender os sentidos de sua participação social.

Conforme os postulados sociodialógicos bakhtinianos, a língua é um aspecto social e por seu intermédio há interação, desse modo o discurso pode assumir diferentes formas. Pelo fato de a enunciação ser, nas palavras do autor, "de natureza social" (BAKHTIN; VOLOCHÍNOV, 1981 [1929], p. 109), descarta-se a possibilidade de esse conceito "[...] ser considerado como individual no sentido estrito do termo; não pode ser explicado a partir das condições psicofisiológicas do sujeito falante." (BAKHTIN; VOLOCHÍNOV, 1981 [1929], p. 109). Ainda segundo Bakhtin (2003 [1930], p. 262), "[...] cada esfera de utilização da língua elabora seus tipos relativamente estáveis de enunciados, os quais denominamos gêneros do discurso". É na relação dialética estabelecida entre os interlocutores que os usos 
sociais da linguagem se tipificam em gêneros discursivos orais ou escritos, dada sua recorrência em determinado contexto sócio-discursivo (BAKHTIN, 2003 [1930]). De modo geral, os gêneros são caracterizados por sua (i) função sócio-discursiva, que indica as condições do contexto de produção de determinado gênero; (ii) função composicional, que expressa aspectos referentes aos elementos que compõem o texto; (iii) função temática, a qual identifica o conteúdo temático e as ideologias materializadas no texto; e (iv) função estilística, que mobiliza recursos lexicais, gramaticais e textuais da enunciação.

Ao tratar mais especificamente da esfera científica, as práticas discursivas do estudo e pesquisa são normatizadas por órgãos reguladores, como é o caso da Associação Brasileira de Normas Técnicas (ABNT) nas suas diferentes normas. Assim, as instituições de ensino também devem assumir a responsabilidade em agregar esse conhecimento à formação do estudante. Com base nesses pressupostos, assume-se para este trabalho, os postulados de Marcuschi (2008, p. 84), apoiado pelos estudos da Linguística Textual, especialmente aqueles relacionados às sequências textuais de Adam (1999 apud MARCUSCHI, 2008). Nessa relação, Marcuschi explicita a necessidade do estudo da articulação entre discurso e texto, vinculando, de forma intrínseca, o plano discursivo ao plano textual. Por isso, propõe-se, para essa pesquisa, a nomenclatura gêneros discursivos/textuais ao invés de utilizar-se somente gênero discursivo, termo normalmente utilizado por pesquisadores da linguística aplicada; ou gênero textual, vocábulo preferido pelos estudiosos da linguística textual, conforme esclarece Rojo (2005), ao tratar dos aspectos conceituais do discurso-texto.

Assumidos como unidade de ensino-aprendizado nas práticas pedagógicas, os gêneros discursivos/textuais compreendem aspectos cognitivos e linguísticos que os constituem como práticas sociais de linguagem. A terceira versão da Base Nacional Comum Curricular (BRASIL, BNCC, 2017) contextualiza o ensino de gêneros, enfocando cinco campos de atuação social: o da vida pessoal, o das práticas de estudo e pesquisa, o jornalístico-midiático, o de atuação na vida pública e o artístico-literário. Aqui cabe uma ressalva sobre a proposta de se manter o sexto campo de atuação, o campo de "práticas do mundo do trabalho", que estava presente na versão preliminar da BNCC de 2015 , mas foi elidida da versão final de 2017.

Também segundo a Base Nacional Comum Curricular (BRASIL, BNCC, 2017), os textos de diferentes campos de atuação social devem ser assumidos como objetos do processo de ensino-aprendizagem de língua portuguesa e como ferramenta nas demais unidades curriculares, conforme os pressupostos do interacionismo sóciodiscursivo, teorizado por Schneuwly e Dolz (2010 [2004]) e Bazerman (2005), por exemplo. Essa perspectiva psicolinguística aplicada em sala de aula propõe uma prática pedagógica de ensino dos gêneros discursivos/textuais em sequências didáticas e busca orientar as práticas de letramento, multiletramento e novos letramentos nos estudantes, considerando-se o desenvolvimento dos domínios cognitivos de diferentes níveis de complexidade. Esse é um processo que demanda aprendizado, conhecimento, leitura e produção dos mais variados gêneros textuais em diferentes campos de atuação social.

Portanto, para atender a esse objetivo no que tange o trabalho com a linguagem em sala de aula, apontando-se para a necessidade de diferentes processos de interação para esse fim, o professor deve assumir um papel de mediador e de 
relevância nas interações, conforme pressupostos teóricos da teoria de aprendizagem sociointeracionista vygotskiana. Essa perspectiva sócio-históricocultural proposta por Vygotsky (2000, 2008 [1978]) para o desenvolvimento da aprendizagem integra os conceitos de Internalização das funções psicológicas superiores, Mediação simbólica, Relações entre o pensamento e a linguagem, Relações entre desenvolvimento e aprendizado, Formação de conceitos, entre outros. Esses conceitos são fundamentais para proporcionar uma ação pedagógica em que o docente assume o papel de orientar os estudantes para os usos adequados da língua materna. Assim, o professor propicia ao aluno "[...] o refinamento de habilidades de leitura e de escrita, de fala e de escuta" (BRASIL, OCEM, 2006, p.18). Entende-se, por isso, que todas as habilidades linguísticas devem ser ampliadas na medida em que o caminho escolar é traçado.

Quando se trata da EPT, é indispensável compreender que a finalidade dessa modalidade educativa possui como eixos norteadores o trabalho como princípio educativo e a pesquisa como princípio pedagógico, como se discutiu anteriormente. Em publicação sobre o tema, as autoras Valer, Brognoli e Lima (2017), pautandose na análise do conteúdo da BNCC (2015), apresentaram uma proposta para o trabalho com a linguagem na Educação Profissional por meio de diferentes gêneros discursivos/textuais orais e escritos. Segundo as autoras, é imprescindível a integração dos gêneros discursivos/textuais inseridos nos diferentes campos de atuação social. Na BNCC (2015), os gêneros discursivos/textuais apontados no campo de trabalho diziam respeito à redação técnica empresarial e pessoal, bem como relatórios profissionais. Deve-se atentar, no entanto, para o fato de, em cada área profissional, haver processos comunicativos escritos e orais específicos. Por isso a relevância de se identificá-los, depreendendo os aspectos que os compõem, para poder trabalhá-los pedagogicamente. Acentua-se que, mesmo os gêneros discursivos/textuais de outros campos, podem ter seu estudo permeado pela temática do mundo do trabalho.

Enfatizando-se o princípio da pesquisa como prática pedagógica, conforme proposta das autoras, os gêneros, que permeiam o trabalho pedagógico nas práticas investigativas da formação geral "[...] devem também ser adotados na educação profissional, em todos os níveis e modalidades, de forma progressiva e mediada por toda a comunidade escolar" (VALER; BROGNOLI; LIMA, 2017, p. 2796). Para as autoras, a prática da pesquisa como princípio educativo requer uma ação integrada com o ensino-aprendizagem dos diversos gêneros discursivos/textuais orais e escritos tanto relacionados à pesquisa como específicos das áreas profissionais. O ensino pela pesquisa aliado ao uso dos gêneros como unidade didática é capaz de proporcionar a emancipação intelectual dos sujeitos em formação por meio do desenvolvimento de habilidades cognitivas complexas necessárias para solucionar problemas reais, constantes no Parecer $n^{\circ} 5$ do Conselho Nacional da Educação de 2011 e, posteriormente, explicitadas pelas Diretrizes Curriculares Nacionais Gerais (BRASIL, DCNGEB, 2013). São, portanto, habilidades imprescindíveis a uma educação de qualidade que forme sujeitos autônomos, capazes de efetuar sua própria leitura de mundo e de intervir na realidade na qual se inserem propondo transformações sociais. Para o desenvolvimento dessas habilidades, as autoras apontam um caminho que se inicia com a leitura de textos com foco em conceitos teóricos do objeto de estudo seguido de produção escrita progressiva de textos orais e escritos, como as "[...] tomadas de notas/fichamento, podendo abarcar gêneros como resumos, diferentes ensaios, 
projetos de pesquisa, relatórios, trabalhos acadêmicos e textos de divulgação da respectiva pesquisa" (VALER; BROGNOLI; LIMA, 2017, p. 2797) além de "seminário, mesa redonda, palestra, painel". Todos esses textos auxiliam no desenvolvimento de habilidades específicas tanto cognitivas como linguísticas.

Essa nova postura pedagógica no desenvolvimento de aprendizagens adquire relevância por meio do trabalho com projetos temáticos e com uma abordagem transversal do conhecimento que constitui diferentes disciplinas e não apenas as de linguagem, fragmentando o mínimo possível o objeto de estudo e demandando novas atitudes para ensinar e aprender. Segundo as Diretrizes Curriculares Nacionais Gerais (BRASIL; DCNGEB, 2013, p. 28), é preciso enriquecer a interdisciplinaridade "[...] por meio de proposta temática trabalhada transversalmente ou em redes de conhecimento e de aprendizagem". Essa perspectiva didática requer, conforme apresenta esse mesmo documento, sobretudo planejamento sistemático e integrado além de abertura para constante diálogo entre diferentes sujeitos, ciências, temas e saberes.

\section{A metodologia da pesquisa}

Considerando-se o objetivo desta pesquisa (identificar as pesquisas empíricas recentes sobre o processo de ensino-aprendizagem de língua materna na Educação Profissional Técnica de Nível Médio Subsequente), quanto à metodologia deste trabalho, escolheu-se a abordagem qualitativa com relação à natureza da pesquisa, por não se revestir de uma formulação matemática e não exprimir, portanto, de acordo com Severino (2007, p. 118) uma relação puramente quantitativa. Em relação às modalidades de pesquisa, considera-se, para esta investigação, a pesquisa principal como sendo de análise de conteúdo, uma vez que o objetivo, ainda conforme Severino (2007, p. 121), é o de "[...] compreender criticamente o sentido manifesto ou oculto das comunicações". A modalidade secundária quanto à sistematização do corpus para análise é a pesquisa bibliográfica, pois, neste caso, os dados foram organizados "[...] a partir do registro disponível, decorrente de pesquisas anteriores." (SEVERINO, 2007, p. 122). Para o uso de uma metodologia científica é imprescindível, ainda segundo Severino (2007, p. 123), discriminá-la, secundariamente, quanto ao próprio objetivo. Por isso, esta pesquisa foi considerada explicativa, justamente por ultrapassar os meros registros e análises dos fenômenos estudados, buscando, inclusive "identificar suas causas".

Quanto aos procedimentos metodológicos e aos instrumentos de pesquisa, escolheram-se as plataformas virtuais Google Acadêmico, Portal CAPES, Scielo e ANPEd, como locais para depreender os dados de análise. Nesses portais, buscouse por artigos científicos, teses e dissertações produzidos entre janeiro de 2008 e julho de 2018, os quais foram identificados por meio dos seguintes descritores: Língua Portuguesa; Educação Profissional de Nível Médio; Técnico subsequente; Linguagem; Língua Materna; Letramento; Ensino; Ensino e Aprendizagem; Leitura; Oralidade; e Escrita. Como variáveis de pesquisa, os dados analisados foram: título, ano de publicação, autores (se havia somente professores de língua materna ou outros professores trabalhando interdisciplinarmente conforme propõem os documentos), enfoque temático ou objeto de pesquisa, objetivo da pesquisa, modalidade e natureza da pesquisa, modalidade principal de pesquisa, sujeitos do Ensino Profissional e resultados encontrados.

(20)




\section{Descrição e análise dos resultados}

Ressalta-se que não foram encontradas dissertações e teses sobre o tema investigado, observando-se que as pesquisas sobre letramento estão mais direcionadas à modalidade EJA do Ensino Médio regular. Especificamente, sobre o letramento em língua materna na Educação Profissional Técnica de Nível Médio foram encontrados quatro artigos científicos, sendo o mais antigo publicado em 2009 e o mais atual em 2017. Desses artigos, dois deles são voltados para a modalidade de Educação de Jovens e Adultos (PROEJA), dois correspondem ao Ensino Médio Integrado e nenhum está relacionado ao técnico subsequente, ao menos não há informações claras quanto a isso. A seguir, passa-se à descrição dos dados encontrados nos respectivos textos.

O primeiro deles é o artigo Formação de leitores: o ensino de Língua Portuguesa em turmas de EJA, produzido por Cavalcante e Alcântara (2009), o qual reflete sobre a elaboração de materiais didáticos de Língua Portuguesa para turmas de EJA a partir da perspectiva do ensino de gêneros textuais. O objetivo da pesquisa foi investigar, junto aos sujeitos estudantes, as suas habilidades de leitura e escrita com foco no uso gramatical adequado às situações interacionais. A metodologia tomou por base a pesquisa-ação, em que a intervenção se deu pela aplicação de uma sequência didática envolvendo estratégias de leitura e escrita de gêneros discursivos/textuais, buscando avaliar o desempenho dos estudantes em relação ao conteúdo gramatical proposto. A ideia foi partir da leitura de textos envolvendo várias dimensões da linguagem para culminar na produção textual de outros textos. No entanto, os gêneros discursivos/textuais não foram especificados claramente no artigo deixando uma visão bastante vaga sobre o objeto de ensino-aprendizagem investigado. Além da análise gramatical, os autores citam que os estudantes puderam refletir sobre situações de formalidade e informalidade por meio do conhecimento das variações linguísticas atribuídas aos diferentes textos produzidos. Como os gêneros discursivos/textuais não foram especificados claramente no estudo, questões como configuração textual e função social dos diferentes textos não foram abordadas. Os autores aplicaram também um questionário aos sujeitos, cujo objetivo era o de depreender a própria percepção acerca das dificuldades relacionadas à leitura e à escrita dos textos trabalhados. Cabe ressaltar ainda, que foram escolhidos como sujeitos de pesquisa estudantes recém ingressados no Ensino Médio na Modalidade de Jovens e Adultos da Educação Profissional no primeiro semestre dos anos de 2006 a 2008. Os resultados encontrados demonstram que os estudantes consideram que ler $\mathrm{e}$ escrever são práticas importantes, mas preferem aquelas que os levem a reflexões ou que sejam atreladas a atividades lúdicas. Tais colocações deram embasamento para que os pesquisadores reelaborassem tanto o material didático utilizado nas aulas de Língua Portuguesa como as práticas pedagógicas para as turmas posteriores. Não aparecem no artigo quais foram essas reelaborações, tampouco qual aspecto das investigações exatamente as motivou.

O segundo artigo que aborda a temática aqui investigada na modalidade de Educação de Jovens e Adultos intitula-se $A$ relação sujeito/língua em produções escritas de estudantes do PROEJA, de White (2015), e discute a maneira como se dá a relação sujeito/língua em produções escritas de alunos do Programa Nacional de Integração da Educação Profissional com a Educação Básica. A autora delineou, como objetivo da pesquisa, a análise de fenômenos linguísticos presentes em 
produções textuais escritas dos estudantes a partir das singularidades da relação sujeito-linguagem. Para isso, o trabalho de White apresenta em sua metodologia uma modalidade de pesquisa principal de abordagem qualitativa, trilhando as seguintes etapas: leitura e seleção dos textos, identificação dos fenômenos linguísticos e, por fim, discussão das singularidades. Como resultado obtido pela pesquisa, a autora relacionou o comportamento linguístico à variedade da língua utilizada pela comunidade da qual os estudantes fazem parte. Além desse aspecto, White evidenciou que as oscilações e hipercorreções se deram por uma preocupação excessiva em escrever na modalidade padrão da língua portuguesa. Por meio desses resultados, a autora conclui sobre a importância de o espaço escolar entender e aceitar a diversidade linguística a fim de garantir a melhor metodologia para o ensino do dialeto padrão.

O terceiro artigo, que aborda a modalidade do Ensino Médio Integrado, de autoria de Cruz et al. (2015), denomina-se Análise da produção científica nos cursos técnicos de nível médio do IFRN campus Pau dos Ferros: Estudo de caso das turmas 2012.1 (2012-2015). Nele os autores reúnem e analisam dados sobre a vivência da escrita acadêmica de projetos e artigos científicos. Para cumprir com os objetivos, a abordagem de pesquisa utilizada foi a qualitativa com a aplicação de um questionário semiestruturado contendo questões dicotômicas, de múltipla escolha e abertas; como modalidades, utilizaram tanto a pesquisa descritiva como a bibliográfica. Os sujeitos da pesquisa foram 97 alunos de três turmas ingressantes em 2012.1 nos cursos técnicos de nível médio de Alimentos, Apicultura e Informática do Campus Pau dos Ferros do IFRN no período de 2012 a 2015. Os resultados obtidos pelos pesquisadores mostraram que apenas $24,7 \%$ dos estudantes dos cursos técnicos analisados participaram de algum projeto de pesquisa; $13,4 \%$ dos alunos estavam incluídos em algum projeto de extensão; $6,2 \%$ inseridos em alguma atividade de estágio; 7,2\% dos estudantes publicaram trabalhos em periódicos científicos e 37,1\% em eventos científicos; e 39,2\% dos estudantes submeteram trabalhos provenientes de projetos em execução ou de pesquisas pontuais. Além disso, os pesquisadores constataram que $24,7 \%$ dos estudantes tiveram iniciativas próprias para o ingresso em atividades de produção científica e $13,4 \%$ receberam incentivo dos professores, que, em muitos casos, utilizaram a pesquisa científica como instrumento das ações pedagógicas em aulas regulares. Ao avaliar o percentual de alunos que participou de projetos de pesquisa e/ou extensão, de eventos científicos, que publicou trabalhos em periódicos e/ou eventos científicos ou submeteu trabalhos para periódicos e/ou eventos científicos, os autores consideraram a iniciação científica no ensino médio um instrumento didático importante para o contato e a experiência com a pesquisa científica na esfera escolar.

Eu leio. Você lê? Desafios e possibilidades no trabalho com o letramento literário, de Dantas et al. (2017), foi o último artigo encontrado. Nele as autoras objetivaramse a analisar quais fatores contribuem para a formação leitora de textos literários, verificando as escolhas que os estudantes fazem de textos literários e conhecendo as dificuldades e facilidades encontradas na leitura dos diferentes gêneros literários. A abordagem metodológica foi a da pesquisa qualitativa e quantitativa, de caráter exploratório, por meio de um questionário de perguntas abertas aplicado a setenta alunos dos cursos Técnico Integrado em Informática e Técnico Integrado em Meio Ambiente do Instituto Federal de Educação, Ciência e Tecnologia da Paraíba (Campus Sousa). Além da análise do questionário, o qual buscou verificar de que 
maneira são feitas as escolhas de textos literários pelos jovens e também conhecer quais dificuldades e facilidades esses estudantes enfrentam quando expostos a esses gêneros; as autoras analisaram também, com base em observações, as percepções sobre a desenvoltura do Clube Leitor, projeto do qual os discentes são convidados a participar. No Clube Leitor, quinze alunos, acompanhados do docente e de bolsistas, realizaram encontros mensais com o objetivo de ler e discutir obras literárias escolhidas de acordo com o interesse individual. Por meio da análise dos questionários, Dantas et al. (2007) constataram que, embora $67 \%$ dos sujeitos participantes indicassem gosto pela leitura, apenas 39\% liam livros literários. Os resultados obtidos pelas autoras apontaram que a falta de incentivo, justamente pela ausência de uma atmosfera motivadora, é um dos elementos que mais distancia o aluno da leitura. Como maneira de superar esse fato, as autoras propõem a necessidade de o docente possuir um conhecimento teórico e metodológico; e caracterizam a importância da mediação, articulando a interação com a discursividade, como elemento favorável ao letramento literário e à formação do leitor. Dessa forma, segundo as autoras, constrói-se uma aproximação entre texto e leitor "[...] mediante o diálogo entre historicidade e contexto sociossubjetivo do aluno" (DANTAS et al., 2017, p. 74).

Os sujeitos dos artigos descritos nesta investigação são alunos da Educação Profissional de nível médio, ou seja, estudantes recém ingressados na EJA (CAVALCANTE; ALCÂNTARA, 2009); estudantes do PROEJA com um dos sujeitos pertencente ao curso técnico de Desenho da Construção Civil (WHITE, 2015); alunos dos cursos técnicos de Informática, Apicultura e Alimentos, sem a informação sobre o tipo de oferta ser integrada ou subsequente (CRUZ et al., 2015); e discentes dos cursos técnicos integrados ao médio em Informática e Meio Ambiente (DANTAS et al., 2017).

Levando-se em consideração a base conceitual que subsidia os documentos das políticas públicas para o ensino e a aprendizagem de língua materna tanto para a formação geral como para a formação profissional, enfatiza-se a necessidade do trabalho com os gêneros discursivos/textuais como objeto pedagógico. Observa-se, conforme a descrição dos dados acima, que, embora de modo geral, os autores tratem em suas pesquisas de gêneros discursivos/textuais como objeto de investigação, não esclarecem nem especificam quais são esses gêneros, utilizandoos mais como um meio para outro fim. Sobre esse aspecto, algumas pesquisas apenas citam alguns dos textos que permearam suas investigações. Cavalcante e Alcântara (2009), por exemplo, fazem alusão à prática da leitura por meio dos gêneros filme, documentário, gravura, entre outros para iniciar as sequências didáticas; e à prática de escrita de gêneros como carta, depoimento, texto jornalístico, listagem de desejos etc. Dantas et al. (2017) mencionam o vídeo explicativo, o conto e o romance como os gêneros literários pelos quais percorreram durante suas investigações. Cruz et al. (2015) expõem dois gêneros do campo da prática de estudo e pesquisa, a escrita de projeto e artigo científico, porém, assim como os demais, não focaliza o ensino dos aspectos textuais e linguísticos atrelados a esses gêneros, tratando-os apenas como meio para investigar a participação dos sujeitos em processos de pesquisa. As pesquisas citadas, atendem às demandas da escola como uma agência de letramento que, conforme salienta Melo e Cavalcante (2006), garante aos sujeitos uma inclusão no mundo letrado e, ao mesmo tempo, a extrapolação do letramento escolar, por meio do domínio de múltiplos contextos, sejam os literários (DANTAS et al., 2017), os científicos (CRUZ 
et al., 2015) ou os da vida pessoal (CAVALCANTE; ALCÂNTARA, 2009), necessários para uma efetiva participação social.

Encontrou-se também uma lacuna nas pesquisas expostas acima quanto ao trabalho progressivo com os gêneros, tendo em vista o desenvolvimento de habilidades cognitivas, o que demandaria, segundo o Parecer $\mathrm{n}^{\circ} 5$ do Conselho Nacional da Educação (BRASIL, PARECER CNE/CEB, 2011), abordá-los dos mais simples aos mais complexos. Ainda assim, percebe-se que, em Dantas et al. (2017), houve preocupação em incentivar atividades mentais de diferentes domínios cognitivos, já que as autoras enfatizam a elaboração de uma sequência didática para o ensino de leitura. Desse modo, promovem a formação de sujeitos capazes de desenvolver mecanismos que os tornem autônomos em suas leituras, passando pela ampliação das habilidades cognitivas relacionadas à compreensão e à análise das obras literárias lidas. Em acréscimo, as pesquisadoras são as únicas que mencionam a importância de conceitos como a interação e a mediação, mesmo que sob a perspectiva do Método Recepcional defendido por elas. Segundo as autoras, "[...] os conhecimentos são construídos pela interação entre leitor e texto, sendo o professor mediador dessas ações" (DANTAS et al., 2017, p. 62). Embora o artigo não cite a teoria de aprendizagem sociointeracionista de Vygotsky (2000, 2008 [1978]), os pressupostos utilizados corroboram os também defendidos e apresentados nesta investigação, pois aqui também se assume a relevância da instituição formal de ensino como agência mediadora da aprendizagem.

Uma vez inexistentes as especificações dos gêneros discursivos/textuais, perde-se também o entendimento dos objetivos que motivaram as escolhas dos textos citados nas pesquisas, considerando-se que cada texto é constituído por aspectos sócio-discursivos, composicionais, temáticos e estilísticos. Em certa medida, a função estilística é abordada por Cavalcante e Alcântara (2009), que salientam a percepção e reflexão dos sujeitos quanto ao estilo textual ser formal ou informal, além de apresentarem uma perspectiva de retomada de conteúdos gramaticais, como pontuação, acentuação e concordância durante a refacção das práticas de produção textual escrita. O trabalho com a função sociotemática dos gêneros pode ser percebida em Cruz et al. (2015), que se preocupam com o vínculo entre o conteúdo dos gêneros citados e os eixos tecnológicos ofertados no local em que se deu a pesquisa; e em Dantas et al. (2017), que focaram a intervenção para a formação de leitores em discussões temáticas sobre os gêneros literários estudados. Para Bakhtin e Volochínov (1981 [1929]), toda enunciação é social e é por intermédio da linguagem que os sujeitos produzem discursos, os quais assumem diferentes formas, mas são sempre constituídos por funções sóciodiscursivas, composicionais, temáticas e estilísticas. Assim, em consonância com esses autores, ressalta-se que o trabalho com gêneros requer uma atenção para os aspectos que os compõem. Sabe-se que, dependendo do objetivo da investigação, é possível que o pesquisador estabeleça um recorte, no entanto é esperado que cada um dos enfoques imanentes ao texto seja abordado minimamente.

Quanto ao campo de atuação, esperava-se encontrar uma mescla quanto à escolha dos gêneros discursivos/textuais em cada pesquisa para que se percebesse uma dinâmica pedagógica envolvendo diferentes campos de atuação social, conforme postulados do documento Base Nacional Comum Curricular (BRASIL, BNCC, 2017). Cavalcante e Alcântara (2009) elaboraram seus estudos sob a perspectiva apenas do campo da vida pessoal; Cruz et al. (2015) enfocou sua pesquisa somente no campo das práticas de estudo e pesquisa; e Dantas et al. (2017) abordou 
unicamente o campo artístico-literário. Embora na última versão da Base Nacional Comum Curricular (BRASIL, BNCC, 2017), o campo de "[...] práticas do mundo do trabalho" não esteja mais presente, como ocorre em versões anteriores desse documento, em se tratando de pesquisas de linguagem na EPT, esperava-se observar gêneros discursivos/textuais contextualizados por esse campo de atuação social, ainda que mesclados com outros campos, como o das práticas de estudo e pesquisa, por exemplo. No entanto, esse aspecto não está contemplado nas pesquisas aqui descritas.

Consequentemente, percebe-se que o tema trabalho pouco ou nada aparece para permear as práticas de leitura e escrita de textos. Nesse quesito, apenas Cruz et al. (2015) apresentam dados sobre esse aspecto relacionados às produções dos estudantes. Segundo os autores, $41,2 \%$ dos estudantes produzem gêneros que relacionam o campo das práticas de estudo e pesquisa à temática trabalho, já que $20,6 \%$ dos sujeitos pesquisados produziram seus textos sobre Apicultura e outros $20,6 \%$ sobre Ciência e Tecnologia de Alimentos, o que condiz com a formação profissional dos cursos investigados. Perceber essa recorrência é importante, pois como são pesquisas elaboradas na Educação Profissional, as temáticas envolvendo a formação para o mundo do trabalho e as especificidades envolvendo cada formação precisam ser recorrentes e permear todas as unidades curriculares, inclusive as de linguagens. Cabe enfatizar ainda sobre o estudo de Cruz et al. (2015), que esse tipo de estudo quantitativo, embora não tenha, nesse caso, o ensino de gêneros como foco, é importante e dialoga com as diferentes possibilidades de situações práticas na Educação Profissional, conforme aponta a Resolução No 6 (BRASIL, RES. N. 6, 2012, p. 6-7), como as experiências adicionais de vivência e aprendizagem por meio de projetos de pesquisa e/ou intervenção.

Além dos elementos analisados, percebe-se que as pesquisas também deixaram lacunas quanto à importância de uma formação humana pautada na indissociabilidade entre as dimensões ciência, tecnologia, trabalho e cultura, conforme os pressupostos presentes nos documentos que regulamentam as políticas educacionais na EPT (BRASIL, Res. $n^{\circ} 6$, 2012; BRASIL, DCNGEB, 2013). Sobre esse aspecto, Cruz et al. (2015) apresentam dados que chamam atenção sobre as produções científicas elaboradas por professores e estudantes dos cursos técnicos de nível médio. Segundo os autores, há um maior envolvimento em pesquisas das áreas técnicas e pouquíssima ou nenhuma realização de pesquisas nas áreas de formação geral. Esse dado é preocupante, uma vez que demonstra ainda uma dualidade entre teoria e prática no ensino que em nada favorece uma educação profissional politécnica, e a formação integrada com o objetivo de formar cidadãs e cidadãos trabalhadores e conscientes de sua história e sua identidade.

Com base na descrição dos dados acima encontrados, é possível estabelecer que a prática pedagógica no ensino e na aprendizagem da língua materna na Educação Profissional Técnica de Nível Médio não necessariamente segue a recomendação dos documentos educacionais legais. Assim, os eixos e princípios que norteiam essa modalidade de ensino, quando negligenciados, colocam em risco uma proposta de educação que proporcione uma formação verdadeiramente integrada ao desenvolver tanto a competência profissional como a social. Assim, o que se percebe, é que nenhum artigo desta investigação apresentou como objetos principais de ensino-aprendizagem da língua materna os gêneros discursivos/textuais. Esse desencontro foge de uma base conceitual importante da EPT que é uma prática educativa solidificada no princípio pedagógico da pesquisa

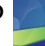


e no princípio educativo do trabalho a fim de desenvolver habilidades cognitivas complexas que levem a uma autonomia intelectual dos sujeitos aprendizes. Salienta-se também que não houve uma preocupação em abordar a função transdisciplinar da língua portuguesa em nenhum dos artigos encontrados, nem o princípio da interdisciplinaridade como alternativa para o ensino fragmentado. A única menção feita à abordagem interdisciplinar foi em Dantas et al. (2017), que chegaram à reflexão de que a pesquisa elaborada sobre a formação de leitores poderia também ser aplicada interdisciplinarmente. $O$ envolvimento de docentes de diferentes áreas do conhecimento não foi reportado pelos autores nos trabalhos encontrados, considerando o recorte estabelecido para esta pesquisa.

É preciso ressalvar, ainda, a impossibilidade de se afirmar que as pesquisas empíricas aqui descritas são as únicas existentes sobre o objeto investigado no período delimitado, uma vez que esses resultados derivam do tipo de busca empreendido em plataformas virtuais específicas por meio dos descritores apresentados na metodologia deste estudo.

\section{Considerações Finais}

Ao se assumir que o recorte desta investigação representa as pesquisas publicadas em plataformas virtuais de grande circulação especificamente para a Educação Profissional de Nível Médio, prioritariamente os cursos subsequentes, os dados aqui apresentados englobam parte do conteúdo científico produzido durante uma década (de 2008 a 2018) e, portanto, demonstram-se insuficientes no tratamento do tema do letramento no ensino-aprendizagem de língua materna na modalidade em questão. Destaca-se que não foram encontradas pesquisas empíricas sobre o objeto investigado em cursos técnicos subsequentes. Entende-se ainda que o desenvolvimento das práticas de letramento por meio do ensino de diferentes gêneros discursivos/textuais, considerando os princípios norteadores da EPT, embora esteja previsto nos documentos oficiais da educação brasileira, ainda carece de pesquisas empíricas e de divulgação científica.

É preciso, ainda, que o trabalho com a linguagem na EPT de Nível Médio esteja fundamentado em práticas pedagógicas interdisciplinares e que o ensino de gêneros discursivos/textuais seja compreendido em sua função transdisciplinar, sendo assumido por todas as áreas, com a finalidade de formar sujeitos que desenvolvam habilidades linguísticas e cognitivas complexas que os tornem capazes de ser e agir consciente e autonomamente no mundo social e profissional. Por fim, é necessário que o conhecimento da base teórica que fundamenta a EPT possa ser acessado pelos docentes dessa modalidade de ensino. Por meio desse conhecimento, os docentes poderão compreender por que é importante fazer escolhas temáticas compatíveis com o campo de formação e atuação profissional para orientar e contextualizar o ensino e a aprendizagem na EPT.

\section{Referências}

BAKHTIN, M.; VOLOCHÍNOV, V. N. Marxismo e filosofia da linguagem: problemas fundamentais do método sociológico na ciência da linguagem. Tradução de Michel Lahud e Yara Frateschi Vieira. 2. ed. São Paulo: Hucitec, 1981 [1929]. 
BAKHTIN, M. Os gêneros do discurso. In: BAKHTIN, M. Estética da criação verbal. Tradução Paulo Bezerra. 4 ed. São Paulo: Martins Fontes, 2003 [19521953].

BAZERMAN, C. Gêneros textuais, tipificação e interação. São Paulo: Cortez, 2005.

BRASIL. Constituição da República Federativa do Brasil: promulgada em 5 de outubro de 1988. Disponível em:

www.planalto.gov.br/ccivil_03/constituicao/constituicao.htm. Acesso em: 20 fev. 2020.

BRASIL. Ministério da Educação. Lei de Diretrizes e Bases da Educação

Nacional. Lei $n^{\circ}$ 9.394, de 20 de dezembro de 1996. Disponível em:

portal.mec.gov.br/arquivos/pdf/ldb. Acesso em: 10 mar. 2020.

BRASIL. Ministério da Educação. Orientações curriculares para o ensino médio. Volume 1: Linguagens, códigos e suas tecnologias, 2006. Disponível em: portal.mec.gov.br/seb/arquivos/pdf/book_volume_01_internet.pdf. Acesso em: 30 mar. 2020.

BRASIL. Educação Profissional e Técnica de Nível Médio integrada ao Ensino Médio: Documento Base. Brasília: MEC, Secretaria de Educação Profissional e Tecnológica, 2007. Disponível em:

http://portal.mec.gov.br/setec/arquivos/pdf/documento_base.pdf. Acesso em: 10 mar. 2020.

BRASIL. Lei $\mathbf{n}^{\circ} \mathbf{1 1 . 7 4 1}$ de 16 de julho de 2008. Altera dispositivos da Lei no 9.394, de 20 de dezembro de 1996, [...]. Diário Oficial da União. Brasília, DF, 16 de jul. 2008. Disponível em: http://www.planalto.gov.br/ccivil_03/_ato20072010/2008/lei/l11741.htm. Acesso em: 10 mar. 2020.

BRASIL. Lei 11.892 de 29 de dezembro de 2008. Institui a Rede Federal de Educação Profissional, Científica e Tecnológica, [...]. Diário Oficial da União. Brasília, DF, 29 de dez. 2008. Disponível em: http://www.planalto.gov.br/ccivil_03/_Ato2007-2010/2008/Lei/L11892.htm. Acesso em: 10 mar. 2020.

BRASIL. Parecer CNE/CEB N. 5/2011. Diretrizes Curriculares Nacionais para o Ensino Médio. Diário Oficial da União, Brasília, 04 de maio de 2011. Disponível em:

http://portal.mec.gov.br/index.php?option=com_docman\&view=download\&alias=99 15-pceb005-11-1-1\&Itemid=30192. Acesso em: 20 fev. 2020.

BRASIL. Parecer CNE/CEB N. 11/2012. Diretrizes Curriculares Nacionais para a Educação Profissional de Nível Médio. Diário Oficial da União, Brasília, 04 de setembro de 2012. Disponível em:

http://portal.mec.gov.br/index.php?option=com_docman\&view=download\&alias $=10$ 804-pceb011-12-pdf\&category_slug=maio-2012-pdf\&Itemid=30192. Acesso em: 20 fev. 2020.

BRASIL. Ministério da Educação. Resolução No 6, de 20 de setembro de 2012. Disponível em: mobile.cnte.org.br:8080/legislacao-externo/rest/lei/51/pdf. Acesso em: 20 fev. 2020. 
BRASIL. Ministério da Educação. Diretrizes Curriculares Nacionais Gerais da Educação Básica. Brasília: MEC, SEB, DICEI, 2013. 542p. Disponível em: file:///C:/Users/User/Downloads/diretrizes_curiculares_nacionais_2013\%20(3).pdf. Acesso em: 10 mar. 2020.

BRASIL. Ministério da Educação. Base Nacional Comum Curricular: consulta pública em 2015. Disponível em:

http://basenacionalcomum.mec.gov.br/images/relatorios-analiticos/BNCCAPRESENTACAO.pdf. Acesso em: 10 out. 2020.

BRASIL. Ministério da Educação. Base Nacional Comum Curricular: proposta preliminar. $2^{a}$ versão revista. 2016. Disponível em:

http://basenacionalcomum.mec.gov.br/images/relatorios-analiticos/bncc-

2versao.revista.pdf. Acesso em: 10 out. 2020.

BRASIL. Ministério da Educação. Base Nacional Comum Curricular: educação é a base. 2017. Disponível em:

http://basenacionalcomum.mec.gov.br/images/BNCC_EI_EF_110518_versaofinal_ site.pdf. Acesso em: 10 ago. 2020.

BRASIL. Lei de Diretrizes e Bases da Educação Nacional. Lei $\mathbf{n}^{0}$ 13.415/2017, de 13 de fevereiro de 2017, Altera as Leis nos 9.394, de 20 de dezembro de 1996, [...]. 2017. Disponível em: http://www.planalto.gov.br/ccivil_03/_ato20152018/2017/lei/L13415.htm. Acesso em: 10 mai. 2020.

CAVALCANTE, llane Ferreira; ALCÂNTARA, Dhierclay de Souza. Formação de leitores: o ensino de Língua Portuguesa em turmas EJA. Revista Holos, Ano 25, v.2, 2009. Disponível em:

http://www2.ifrn.edu.br/ojs/index.php/HOLOS/article/view/204/197. Acesso em: 30 mar. 2020.

CRUZ, Carlos Eduardo Ferreira et al. Análise da produção científica nos cursos técnicos de nível médio do IFRN campus Pau dos Ferros: Estudo de caso das turmas 2012.1 (2012-2015). Revista Brasileira de Educação Profissional Tecnológica, IFRN, v.2, n.9, p. 32-40, dez. 2015. Disponível em: http://www2.ifrn.edu.br/ojs/index.php/RBEPT/article/view/3548/1260. Acesso em: 30 mar. 2020.

DANTAS, Maria Leuziedna et al. Eu leio. Você lê? Desafios e possibilidades no trabalho com o letramento literário. VÉRTICES, Campos dos Goytacazes/RJ, v.19, n.1, p. 59-75, jan./abr. 2017. Disponível em:

http://essentiaeditora.iff.edu.br/index.php/vertices/article/view/6953/7190. Acesso em: 30 mar. 2020.

FRIGOTTO, Gaudêncio. Trabalho - educação e tecnologia: treinamento polivalente ou formação politécnica? In: DA SILVA, Tomaz Tadeu (org). Trabalho, educação e prática social: por uma teoria da formação humana. Porto Alegre: Artes Médicas, p. 254-74, 1991.

FRIGOTTO, Gaudêncio; CIAVATTA, Maria; RAMOS, Marise. Ensino médio integrado: concepção e contradições. São Paulo: Cortez, 2005.

KLEIMAN, Angela B. (Org.). Os significados do letramento: uma nova perspectiva sobre a prática social da escrita. Campinas: Mercado das Letras, 1995. 294 p. 
MARCUSCHI, L. A. Produção textual, análise de gêneros e compreensão. São Paulo: Parábola Editorial, 2008.

MELO, CTV; CAVALCANTE, MCB. Superando os obstáculos de avaliar a oralidade. In: Marcuschi, B; Suassuna, L (Orgs.). Avaliação em língua

portuguesa. Belo Horizonte: Autêntica; 2006.

PACHECO, Eliezer Moreira. Os Institutos Federais: uma revolução na educação profissional e tecnológica. Natal: IFRN, 2010. Disponível em:

http://memoria.ifrn.edu.br/handle/1044/1013. Acesso em: 10 mai. 2020.

RAMOS, Marise Nogueira. Concepção do ensino médio integrado. Texto apresentado em seminário promovido pela Secretaria de Educação do Estado do Pará nos dias 8 e 9 de maio de 2008, v.8, 2008. Disponível em:

http://forumeja.org.br/go/sites/forumeja.org.br.go/files/concepcao_do_ensino_medi o_integrado5.pdf. Acesso em: 13 ago. 2020.

ROJO, Roxane. Alfabetização e letramento: perspectivas linguísticas. Campinas: Mercado de Letras, 1998.

ROJO, R. Gêneros do discurso e gêneros textuais: questões teóricas e aplicadas. In: MEURER, J. L.; BONINI, A.; MOTTA-ROTH, D. (Orgs.). Gêneros: teorias, métodos, debates. São Paulo: Parábola, 2005.

SAVIANI, Dermeval. Sobre a concepção de politecnia. Rio de Janeiro: EPSJV/Fiocruz, 1989.

SAVIANI, Dermeval. O choque teórico da Politecnia. In: Trabalho, Educação e Saúde, Rio de Janeiro, FIOCRUZ/EPSJV, v.1, n.1, mar. 2003. Disponível em: https://www.scielo.br/pdf/tes/v1n1/10.pdf. Acesso em: 13 ago. 2020.

SCHNEUWLY, B.; DOLZ, J. Os gêneros escolares - das práticas de linguagem aos objetos de ensino. In: SCHNEUWLY, B.; DOLZ, J. Gêneros orais e escritos na escola. Tradução e organização: Roxane Rojo e Glaís S. Cordeiro. Campinas, SP: Mercado de letras, 2010 [2004]. 2.ed.

SEVERINO, A. J. Metodologia do trabalho científico. 23. ed. rev. E atual. - São Paulo: Cortês, 2007.

SOARES, Magda. Letramento: um tema em três gêneros. Belo Horizonte: Autêntica Editora, 1998.

VALER, Salete; BROGNOLI, Ângela; LIMA, Laura. A pesquisa como princípio pedagógico na Educação Profissional Técnica de Nível Médio para a Constituição do ser social e profissional. Fórum linguístico, Florianópolis, v.14, n.4, p. 27852803, out./dez. 2017. Disponível em:

https://periodicos.ufsc.br/index.php/forum/article/download/1984-8412.../35788. Acesso em: 10 ago. 2020.

VYGOTSKY, L. S. A construção do pensamento e da linguagem. 1. ed. São Paulo: Martins Fontes, 2000.

VYGOTSKY, L. S. A formação social da mente. 7. ed. São Paulo: Martins Fontes, 2008 [1978].

WHITE, Marlúcia Alves Secundo. A relação sujeito/língua em produções escritas de estudantes do PROEJA. VÉRTICES, Campos dos Goytacazes/RJ, v.17, n.1, p. 59-74, jan./abr. 2015. Disponível em: 
https://www.academia.edu/42117800/A_rela\%C3\%A7\%C3\%A3o_sujeito_I\%C3\%A Dngua_em_produ\%C3\%A7\%C3\%B5es_escritas_de_estudantes_do_PROEJA.

Acesso em: 30 mar. 2020.

Recebido: $15 / 05 / 20$

Aprovado: 19/09/20

Como citar: MICHELON, R. D.; VALER, S. Pesquisas empíricas sobre o processo de ensinoaprendizagem em língua materna na Educação Profissional Técnica de Nível Médio Subsequente.

Revista de Estudos e Pesquisas sobre Ensino Tecnológico (EDUCITEC), v. 6, e128920, 2020.

Direito autoral: Este artigo está licenciado sob os termos da Licença Creative Commons-

Atribuição 4.0 Internacional. 